\title{
Eculizumab in gemcitabine-induced thrombotic microangiopathy: experience of the French thrombotic microangiopathies reference centre
}

Maximilien Grall ${ }^{1,2}$, Florence Daviet ${ }^{3,2}$, Noémie Jourde Chiche ${ }^{3,2}$, François Provot ${ }^{4,2}$, Claire Presne ${ }^{5,2}$, Jean-Philippe Coindre ${ }^{6,2}$, Claire Pouteil-Noble ${ }^{7,2}$, Alexandre Karras ${ }^{8}$, Dominique Guerrot ${ }^{9}$, Arnaud François ${ }^{10}$, Ygal Benhamou ${ }^{11,2}$, Agnès Veyradier ${ }^{12,2}$, Véronique Frémeaux-Bacchi ${ }^{13,2}$, Paul Coppo ${ }^{14,2}$ and Steven Grangé , $^{*}$

\begin{abstract}
Background: Gemcitabine is a broadly prescribed chemotherapy, the use of which can be limited by renal adverse events, including thrombotic microangiopathy (TMA).

Methods: This study evaluated the efficacy of eculizumab, a monoclonal antibody targeting the terminal complement pathway, in patients with gemcitabine-induced TMA (G-TMA). We conducted an observational, retrospective, multicenter study in 5 French centres, between 2011 and 2016.

Results: Twelve patients with a G-TMA treated by eculizumab were included. The main characteristics were acute renal failure (100\%), including stage 3 acute kidney injury (AKI, 58\%) and renal replacement therapy (17\%), hypertension (92\%) and diffuse oedema (83\%). Eculizumab was started after a median of 15 days (range 4-44) following TMA diagnosis. A median of 4 injections of eculizumab was performed (range 2-22). Complete hematological remission was achieved in 10 patients (83\%) and blood transfusion significantly decreased after only one injection of eculizumab (median of 3 packed red blood cells (range $0-10$ ) before treatment vs 0 (range 0-1) after one injection, $P<0.001)$. Two patients recovered completely renal function $(17 \%)$, and 8 achieved a partial remission (67\%). Compared to a control group of G-TMA without use of eculizumab, renal outcome was more favourable. At the end of the follow up, median eGFR was $45 \mathrm{vs} 33 \mathrm{ml} / \mathrm{min} / 1.73 \mathrm{~m}^{2}$ respectively in the eculizumab group and in the control group.
\end{abstract}

Conclusions: These results suggest that eculizumab is efficient on haemolysis and reduces transfusion requirement in G-TMA. Moreover, eculizumab may improve renal function recovery.

Keywords: Coagulation, thrombotic disorders and therapies, Cancer and thrombosis, Eculizumab, Gemcitabineinduced thrombotic microangiopathy

\footnotetext{
* Correspondence: steven.grange@chu-rouen.fr

${ }^{1}$ Medical Intensive Care Unit, Rouen University Hospital, 37 boulevard Gambetta, 76031 Rouen Cedex, France

${ }^{2}$ French TMA Reference Centre, Hopital Saint-Antoine, Sorbonne Université, AP-HP, Paris, France

Full list of author information is available at the end of the article
}

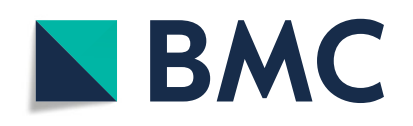

(- The Author(s). 2021 Open Access This article is licensed under a Creative Commons Attribution 4.0 International License, which permits use, sharing, adaptation, distribution and reproduction in any medium or format, as long as you give appropriate credit to the original author(s) and the source, provide a link to the Creative Commons licence, and indicate if changes were made. The images or other third party material in this article are included in the article's Creative Commons licence, unless indicated otherwise in a credit line to the material. If material is not included in the article's Creative Commons licence and your intended use is not permitted by statutory regulation or exceeds the permitted use, you will need to obtain permission directly from the copyright holder. To view a copy of this licence, visit http://creativecommons.org/licenses/by/4.0/. The Creative Commons Public Domain Dedication waiver (http://creativecommons.org/publicdomain/zero/1.0/) applies to the data made available in this article, unless otherwise stated in a credit line to the data. 


\section{Key points}

- In G-TMA, eculizumab is efficient in controlling the hematological disorders and may improve renal function recovery

- C5b9 deposits in kidney biopsies suggest the role of complement activation in gemcitabine-induced TMA

\section{Background}

Thrombotic microangiopathy (TMA) syndromes are characterized by a microangiopathic hemolytic anemia, peripheral thrombocytopenia, and organ injury of variable severity [1]. The principal subtypes of TMA are thrombotic thrombocytopenic purpura (TTP) mainly due to anti-ADAMTS13 autoantibodies and the hemolytic uremic syndrome (HUS) associated with shigatoxin-related endothelial toxicity (shiga-toxin related HUS) or with complement alternative pathway dysregulation (atypical HUS or aHUS). TMA may also result from drug exposure, the most usual agents being calcineurin inhibitors, quinine, antiplatelet agents as well as antineoplastic agents [2]. Gemcitabine is a pyrimidine antimetabolite used for the treatment of a wide range of malignancies. The reported incidence of gemcitabineinduced TMA (G-TMA) in the literature was initially low $(0.015 \%)$ [3] but but a rising number of cases have since been documented with the increasing use of gemcitabine [4-7].

Beyond permanent discontinuation of gemcitabine and supportive care, the optimal management of G-TMA is not well codified [5, 8]. As opposed to TTP, G-TMA generally responds poorly to therapeutic plasma exchange (TPE) and prognosis is dismal [9]. Although there is no complement alternative pathway-related abnormalities described, the severe renal injury and normal ADAMTS13 are reminiscent of HUS, in which complement blockade is remarkably efficient [10]. Single reports suggested the efficacy of eculizumab in G-TMA [11], a monoclonal antibody directed against the complement protein $\mathrm{C} 5$ that has been approved for treatment of atypical HUS. In this context, the present study evaluated the efficacy of eculizumab in a retrospective series of patients with G-TMA.

\section{Methods}

\section{Study design}

We conducted an observational, retrospective, multicenter study including all patients with G-TMA treated by eculizumab in 5 French centres, between 2011 and 2016.

\section{Patients}

Patients who were included in the study met the following criteria: evidence of microangiopathic hemolytic anemia, including schistocytes on peripheral blood smear, thrombocytopenia $(<150 \mathrm{G} / \mathrm{L})$, increased lactate dehydrogenase levels (> Upper limit of normal), low serum haptoglobin < normal and/or renal TMA proven by kidney biopsy. Only one of these criteria could be missing. The diagnosis was retained by the team which took charge of the patient with discontinuation of treatment with gemcitabine. Patients with a TMA attributed to an uncontrolled cancer, as defined by erythroblastosis, metastatic bone marrow infiltration, impaired general condition, and low-cumulative dose gemcitabine $(<5000$ $\mathrm{mg} / \mathrm{m}^{2}$ ) were excluded [11-13]. Patients treated with another chemotherapy concomitantly with gemcitabine were excluded. Patients with a positive shiga-toxin or ADAMTS13 activity $<10 \%$ were also excluded.

Patients were treated with eculizumab according to the regimen previously reported [14]. It consisted generally in 4 weekly infusions $900 \mathrm{mg}$ IV. In responders, a maintenance treatment was started every 2 weeks at week 5, $1200 \mathrm{mg}$. The number of infusions was left at the discretion of the practitioner.

Hematological and renal responses were evaluated, based on data that were systematically extracted from the clinical record. Hematological response was defined by normalization of hematologic values (a normal platelet count and lactate dehydrogenase level) as previously described [14]. The transfusion needs were calculated over a period going from the admission of the patient to the end of the treatment with eculizumab. Renal response was considered as complete if serum creatinine level returned to baseline and as partial if serum creatinine level decreased by $15 \%$ or more.

Acute renal injury (AKI) was assessed according to KDIGO classification 2012. To make possible the comparison between the two groups, we chose to use the CKD-EPI formula for the estimation of the eGFR (glomerular filtration rate), despite we are aware of the limits in the context of AKI. The eGFR of dialysed patients was estimated at $0 \mathrm{ml} / \mathrm{min}$.

We compared patients with G-TMA treated with eculizumab with a control cohort of patients who did not receive eculizumab treatment. Using the French national network, 14 patients were selected using criteria of G-TMA described above without eculizumab therapy. Patients were matched by age and baseline renal function.

This study was approved by the institutional review board of Rouen University Hospital in accordance with the Declaration of Helsinki, and the French Data Protection Authority ("Commission Nationale Informatique et Libertés," CNIL, authorization n ${ }^{\circ} 911,539$, and "Comité consultatif sur le traitement de l'information en matière de recherche dans le domaine de la santé," CCTIRS, authorization $n^{\circ} 11.537$, Paris, France). 


\section{Statistical methods}

Median with range and percentage (\%) were respectively determined for continuous and categorical variables. Differences between groups were assessed by the chi-square test or Fisher's exact test for categorical variables and by the Mann-Whitney U test for continuous variables [15].

\section{Results}

Twelve patients with a G-TMA treated by eculizumab were included ( 10 women, 2 men). None had a past history of chronic renal failure. Gemcitabine was prescribed for ovarian $(n=5,41.7 \%)$, pancreatic $(n=4,33.3 \%)$, pulmonary $(n=2,16.7 \%)$ or uterine $(n=1,8.3 \%)$ cancer. TMA occurred after a median of 6 months (range 1.716) after initiation of gemcitabine and a median cumulative dose of $31.2 \mathrm{~g}$ (range, 9.0-48.0) (Table 1). The main characteristics were microangiopathic hemolytic anemia (100\%), thrombocytopenia (92\%), acute renal failure (100\%), including stage 3 acute kidney injury (AKI, 58\%), and renal replacement therapy (17\%), hypertension (92\%) and diffuse oedema (83\%). The median maximum serum creatinine level was $21 \mathrm{mg} / \mathrm{l}$ (range, 10-76). Quantitative analysis of the complement alternative pathway (CFH, CFI, C3, C1 inhibitor, CD46/MCP and anti-factor $\mathrm{H}$ antibodies) was available in 9 patients (75\%), and revealed no factor deficiency (Supplemental data). Screening for genetic mutation was performed for one patient and was negative (Genes assessed were factor $\mathrm{H}$, factor I, factor $\mathrm{B}, \mathrm{MCP}, \mathrm{C} 3$ and thrombomodulin). Bone marrow aspiration was realized in 4 patients with no evidence of metastatic infiltration.

Renal TMA was proven by kidney biopsy in 3 cases. We compared our patients with 4 patients who had a kidney biopsy for glomerular diseases (minimal change disease was used as a comparator because in this pathology there are usually no deposits of complement on the renal biopsy). By immunofluorescence, we found deposits of the membrane attack complex C5b9 along the glomerular and tubular membrane and also in the capillary wall in our patients as compared to control patients, suggesting the activation of complement cascade in this form of TMA (Fig. 1).

All patients had their gemcitabine treatment stopped. First-line therapeutic plasma exchange (TPE) was performed in 5 patients (42\%), with a median of 7 sessions (range 4-9) without significant benefit on hemolysis or renal function recovery. Eculizumab was started after a median delay of 15 days (range 4-44) following TMA diagnosis. A median of 4 injections $(900 \mathrm{mg} /$ injection, total $3600 \mathrm{mg}$ ) of eculizumab was administered (range 2-22). Of note, only three patients had received more than four injections of eculizumab. Hematological response was obtained in 10 patients (83\%) and blood transfusion significantly decreased after the first infusion of eculizumab (median of 3 packed red blood cells (range $0-10$ ) before treatment vs 0 (range $0-1$ ) after one injection, $p<0.001$ ) (Fig. 2). Two patients recovered renal function completely (17\%), and 8 achieved a partial renal response (67\%), with a median reduction of 8.5 $\mathrm{mg} / \mathrm{l}$ of maximum creatinine level (range 2.5-47) (Table 1). After a median follow-up of 13 months, seven patients (58\%) had persistent chronic renal failure with an estimated glomerular filtration rate (eGFR) below $60 \mathrm{ml} /$ $\mathrm{min} / 1.73 \mathrm{~m}^{2}$. No treatment-associated adverse event was reported. Especially, no meningococcal infection was recorded during follow-up. No exacerbation or relapse of TMA were recorded after eculizumab discontinuation. Six patients $(50 \%)$ died during follow-up, as an indirect complication of TMA with hemorrhagic shock (1 case) despite eculizumab treatment, or to cancer progression after a median of 9 months (range 2-13) following eculizumab initiation (5 cases). Six patients $(50 \%)$ were in complete hematological response and at least partial renal response of TMA after eculizumab discontinuation allowing a switch to another antineoplastic agent (Table $1)$.

We compared patients with G-TMA treated with eculizumab with a control cohort of 14 patients who didn't receive eculizumab treatment (Table 2). TPE were performed in 8 of them. Median baseline eGFR was comparable in the 2 groups, $95(47-147) \mathrm{ml} / \mathrm{min} / 1.73 \mathrm{~m}^{2}$ in the control group and $106(59-132) \mathrm{ml} / \mathrm{min} / 1.73 \mathrm{~m}^{2}$ in the eculizumab group. Compared to the control cohort, patients with G-TMA treated by eculizumab had a better renal outcome (Fig. 3). 83\% of patients in eculizumab group had improvement of their renal function versus $64 \%$ in control group, and median eGFR was $45(0-119)$ vs $33(0-66) \mathrm{ml} / \mathrm{min} / 1.73 \mathrm{~m}^{2}$ respectively at the end of the follow up (Table 3 ). Of note, 2 patients (16\%) still had end stage renal failure in the eculizumab group versus 3 patients (21\%) in the control group.

\section{Discussion}

We report here the largest case series of G-TMA treated by eculizumab. In our patients, we found that the transient use of eculizumab was efficient in controlling the hematologic disorders, by reducing significantly transfusion needs and by correcting thrombocytopenia. Remarkably, hematologic improvement was usually observed just after the two first injections of eculizumab, which strongly suggests a therapeutic action of eculizumab. However, we cannot rule out the hypothesis that the decrease in transfusion requirements was linked to the elimination of gemcitabine after discontinuation of this treatment. As in atypical HUS [14, 16], the use of eculizumab in G-TMA may improve renal function recovery. Indeed, $83 \%$ of patients in our study had a complete or partial renal remission within 2 to 4 weeks 


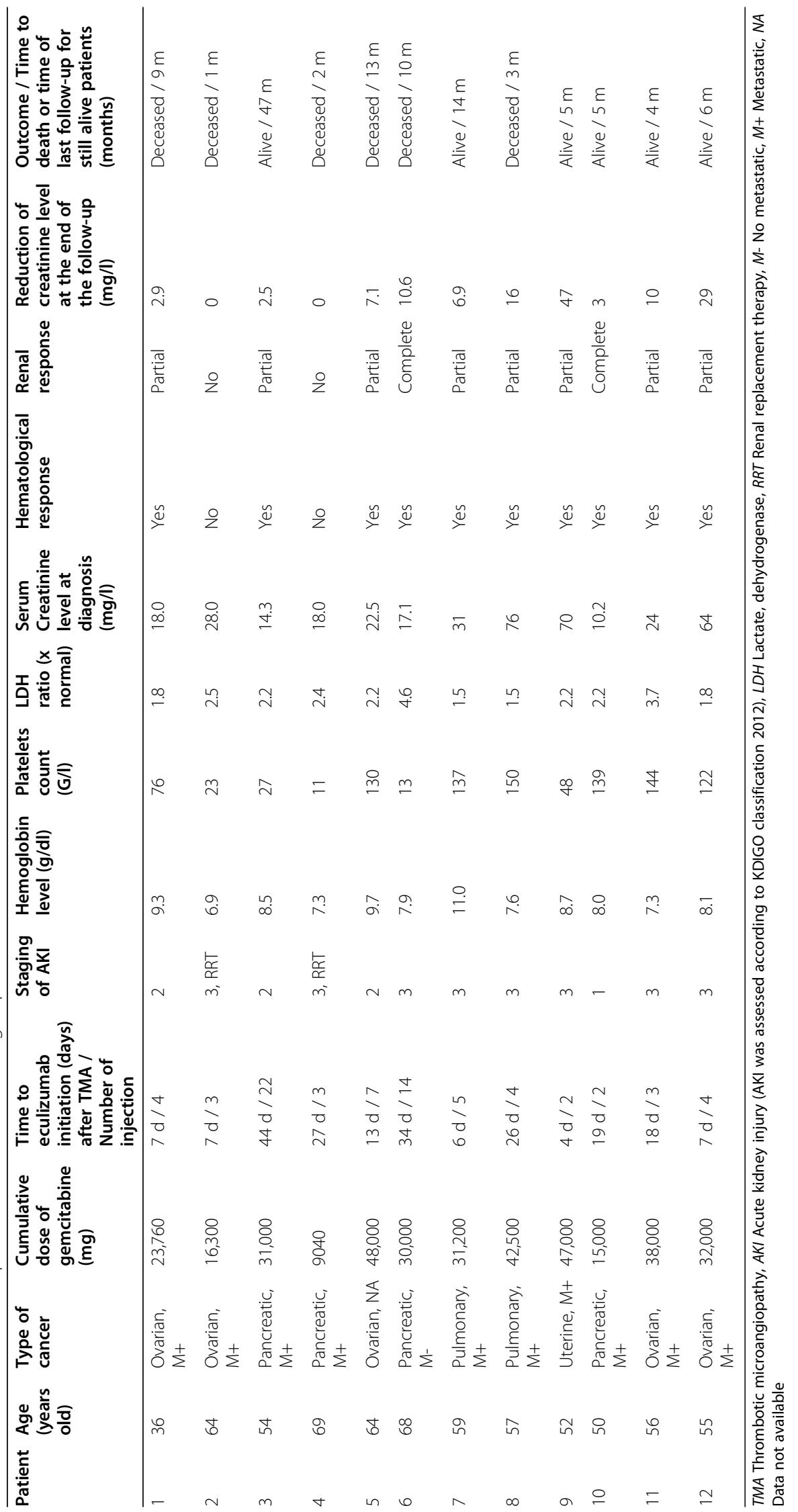



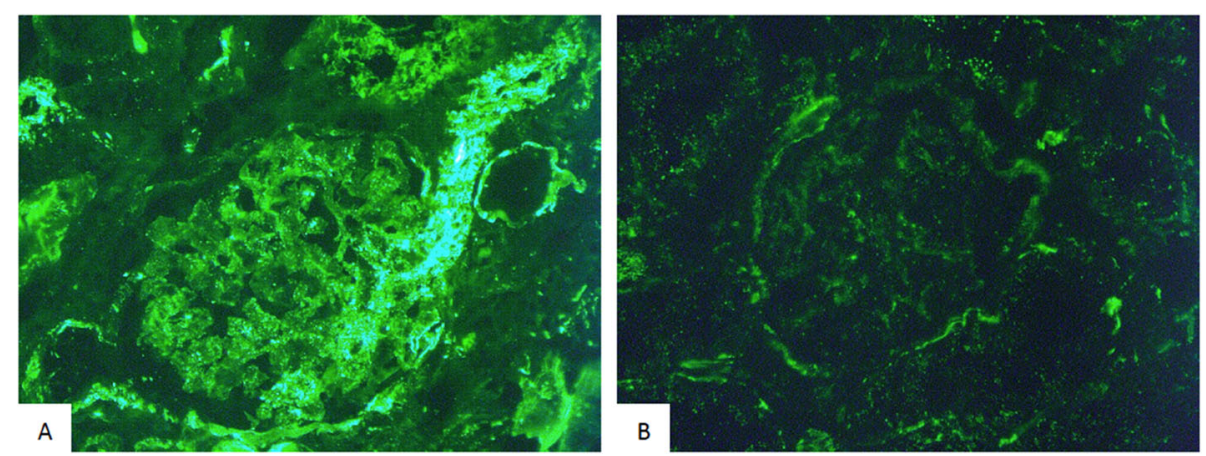

Fig. 1 Kidney biopsy in gemcitabine-induced TMA. By immunofluorescence, kidney biopsy of G-TMA patients (A) showed deposits of membrane attack complex C5b9 in the glomerular and tubular membrane and also in the capillary walls, as compared to control patients with glomerular disease (minimal change disease) (B)

after complement blockade, suggesting again that eculizumab was efficient in controlling TMA. This two-step response with first a rapid improvement in cytopenias after the initiation of eculizumab followed by a more progressive renal improvement is reminiscent of the schedule of response observed in atypical HUS [14].

The pathophysiology of G-TMA is not well established. However, our data show C5b9 deposits in kidney biopsies supporting the hypothesis that the pathophysiology of G-TMA is at least partially related to complement activation, which may result from a direct endothelial toxicity of the drug. This transient complement activation seems to have no genetic background. A

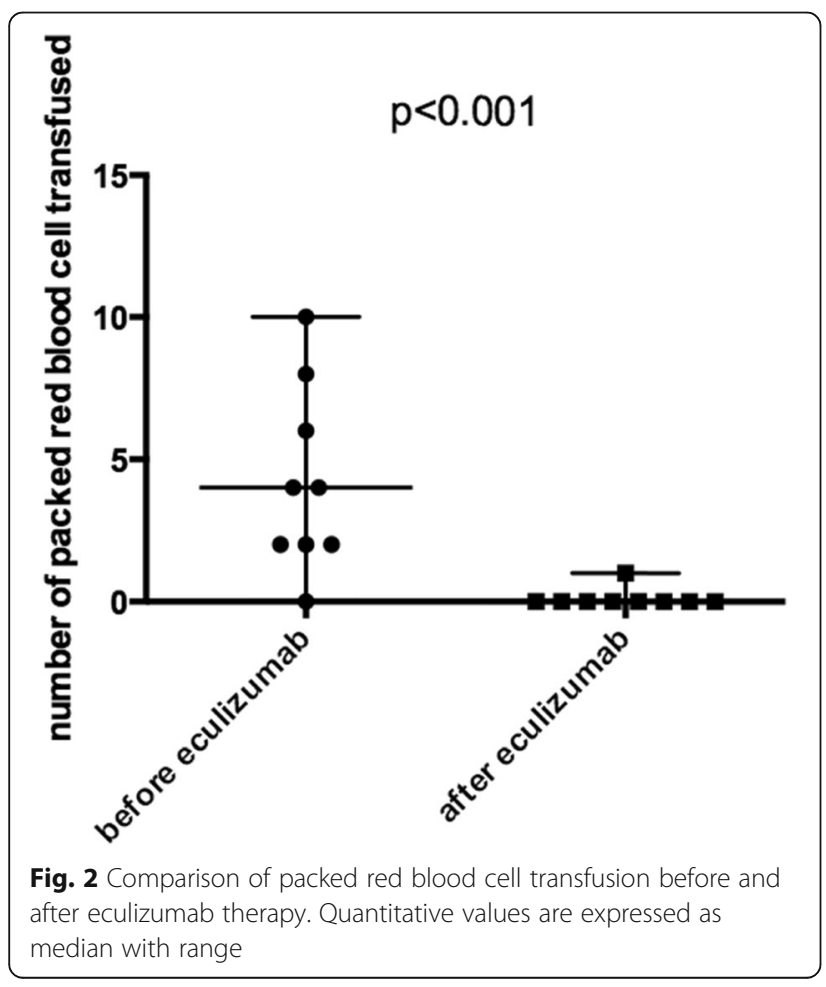

recent work has not revealed any pathogenic variant involved in the regulation of the alternate pathway of complement [17]. There still remains little evidence for quantitative analyses of complement proteins as valid biomarkers.

Reports of patients with G-TMA treated by eculizumab are rare [18-27]. To our knowledge, only 13 cases have been reported in literature, and a similar good outcome was observed. However, these results must be interpreted with caution due to publication bias. As opposed to the hematological response, renal remission is generally observed later and may occur after several weeks because of the process of endothelial healing. One could hypothesize that, similar to atypical HUS, an earlier initiation of eculizumab could allow a greater improvement in renal function recovery [14]. Moreover, there has been no exacerbation or relapse of TMA following eculizumab discontinuation, suggesting that a limited number of infusions may be sufficient to control the TMA process, in association with definitive gemcitabine withdrawal.

Although eculizumab raises cost concerns, these considerations should be weighted against a decreased burden of care, including lower transfusion needs, reduced needs for TPE, and possibly less renal replacement therapy with reduced length of hospitalisation in the intensive care unit during the early stages of AKI. As a result, this strategy could allow a significant improvement in patients' quality of life, particularly when the underlying malignancy has a favourable prognosis.

Our results have the usual limitations of those of a retrospective study, in particular concerning the probable presence of confounding factors; moreover, the number of patients is relatively limited. Therefore, further larger controlled studies are needed to definitely confirm our results, which will be very difficult given the rarity of the disease. These studies should also address whether gemcitabine should be considered 
Table 2 Characteristics of patients in the control group

\begin{tabular}{|c|c|c|c|c|c|c|c|c|c|c|}
\hline Patient & $\begin{array}{l}\text { Age } \\
\text { (years } \\
\text { old) }\end{array}$ & $\begin{array}{l}\text { Type of } \\
\text { cancer }\end{array}$ & $\begin{array}{l}\text { Staging } \\
\text { of AKI }\end{array}$ & $\begin{array}{l}\text { Hemoglobin } \\
\text { level (g/dl) }\end{array}$ & $\begin{array}{l}\text { Platelets } \\
\text { count } \\
\text { (G/I) }\end{array}$ & $\begin{array}{l}\text { LDH } \\
\text { ratio (x } \\
\text { normal) }\end{array}$ & $\begin{array}{l}\text { Serum } \\
\text { Creatinine } \\
\text { level at } \\
\text { diagnosis } \\
(\mathrm{mg} / \mathrm{l})\end{array}$ & $\begin{array}{l}\text { Hematological } \\
\text { response }\end{array}$ & $\begin{array}{l}\text { Renal } \\
\text { response }\end{array}$ & $\begin{array}{l}\text { Outcome / Time to } \\
\text { death or time of last } \\
\text { follow-up for still alive } \\
\text { patients (months) }\end{array}$ \\
\hline 1 & 56 & $\begin{array}{l}\text { Pancreatic, } \\
\text { NA }\end{array}$ & 3 & 12.3 & 79 & 1.9 & 44 & Yes & Partial & Deceased / $72 \mathrm{~m}$ \\
\hline 2 & 33 & $\begin{array}{l}\text { Ovarian, } \\
\mathrm{M}+\end{array}$ & 2 & 6.2 & 58 & 1.4 & 18 & Yes & Partial & Deceased / $10 \mathrm{~m}$ \\
\hline 3 & 80 & $\begin{array}{l}\text { Pancreatic, } \\
\mathrm{M}+\end{array}$ & 2 & 7.3 & 81 & 1.7 & 10 & Yes & Complete & Deceased / $14 \mathrm{~m}$ \\
\hline 4 & 65 & $\begin{array}{l}\text { Pancreatic, } \\
\mathrm{M}+\end{array}$ & 3 & 9.7 & 70 & 1.2 & 35 & Yes & Partial & Deceased / $18 \mathrm{~m}$ \\
\hline 5 & 74 & $\begin{array}{l}\text { Pancreatic, } \\
\mathrm{M}+\end{array}$ & 3, RRT & 9.7 & 34 & 2.9 & 35 & No & No & Alive / $3 \mathrm{~m}$ \\
\hline 6 & 66 & $\begin{array}{l}\text { Pulmonary, } \\
\text { NA }\end{array}$ & 3, RRT & 4 & 146 & 3.9 & 94 & Yes & No & Deceased / $1 \mathrm{~m}$ \\
\hline 7 & 59 & $\begin{array}{l}\text { Pancreatic, } \\
\mathrm{M}+\end{array}$ & 3 & 6.9 & 85 & 1.5 & 41 & Yes & Partial & Alive / $3 \mathrm{~m}$ \\
\hline 8 & 55 & $\begin{array}{l}\text { Pancreatic, } \\
\text { M- }\end{array}$ & 3 & 8.7 & 100 & 3.0 & 41 & Yes & No & Deceased / $2 \mathrm{~m}$ \\
\hline 9 & 78 & $\begin{array}{l}\text { Pancreatic, } \\
\text { M- }\end{array}$ & 3 & 7.2 & 450 & 1.0 & 29 & Yes & Complete & Alive / $24 \mathrm{~m}$ \\
\hline 10 & 56 & Breast, M+ & 2 & 7.5 & 61 & 1.0 & 17 & Yes & Complete & Alive / $2 \mathrm{~m}$ \\
\hline 11 & 58 & Hepatic, NA & 3, RRT & 10.4 & 42 & 6.5 & 32.4 & Yes & No & Deceased / $8 \mathrm{~m}$ \\
\hline 12 & 60 & $\begin{array}{l}\text { Pancreatic, } \\
\mathrm{M}+\end{array}$ & 3 & 8.7 & 202 & 2.5 & 23 & Yes & No & Deceased / $7 \mathrm{~m}$ \\
\hline 13 & 52 & $\begin{array}{l}\text { Hepatic, } \\
\text { M+ }\end{array}$ & 3 & 9.1 & 96 & 5.8 & 50 & Yes & Partial & Deceased / $10 \mathrm{~m}$ \\
\hline 14 & 73 & $\begin{array}{l}\text { Pancreatic, } \\
\text { NA }\end{array}$ & 3 & 9.9 & 430 & 3.1 & 29 & Yes & Partial & Deceased / $14 \mathrm{~m}$ \\
\hline
\end{tabular}

TMA Thrombotic microangiopathy, AKI Acute kidney injury (AKI was assessed according to KDIGO classification 2012), LDH Lactate dehydrogenase, RRT Renal replacement therapy, $M$ - No metastatic, $M+$ Metastatic, NA Data not available

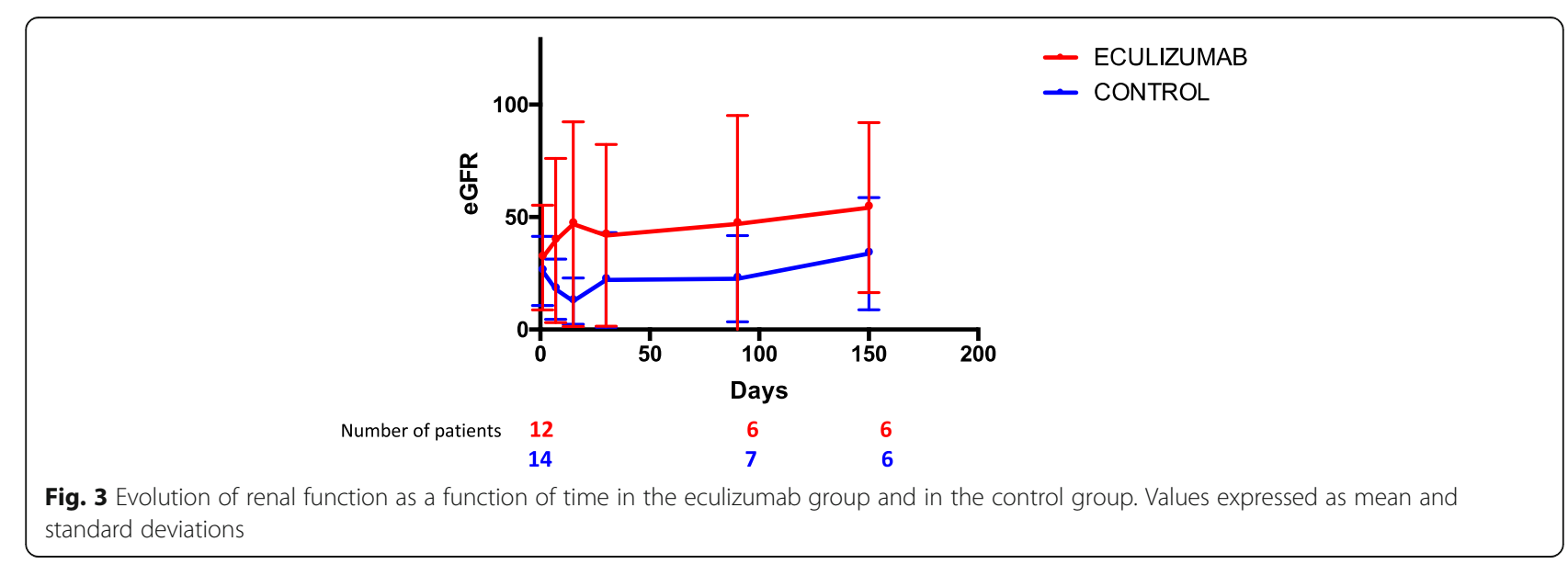


Table 3 Outcome of patients

\begin{tabular}{lll}
\hline & $\begin{array}{l}\text { Eculizumab group } \\
\mathbf{N = 1 2 ( \% )}\end{array}$ & $\begin{array}{l}\text { Control group } \\
\boldsymbol{N}=\mathbf{1 4}(\%)\end{array}$ \\
\hline Renal response & $10(83)$ & $9(64)$ \\
Partial & $8(66)$ & $6(43)$ \\
complete & $2(17)$ & $3(21)$ \\
eGFR at onset $\left(\mathrm{ml} / \mathrm{min} / 1.73 \mathrm{~m}^{2)}\right.$ & $19(0-76)$ & $12(0-31)$ \\
eGFR at the end of follow up & $45(0-119)$ & $33(0-66)$ \\
\hline eGFR Estimated glomerular filtration rate. Quantitative values are expressed as \\
median with range
\end{tabular}

contraindicated after resolution of G-TMA. Only one patient had a genetic evaluation of the alternative complement pathway. Nevertheless, in France, a quantitative analysis of the complement is sometimes carried out in this context of TMAs secondary to gemcitabine. If this is abnormal, it is completed by the genetic evaluation. We now know that there is no pathogenic variant found in secondary TMAs in the vast majority of patients [17]. On the other hand, our study rather suggests a transient activation of the alternate pathway of complement. Finally, there were analyzable kidney biopsies in just 3 patients, so it is difficult to draw broad conclusions about the findings in G-TMA.

Aknowledgements The members of the Reference Centre for Thrombotic Microangiopathies (CNR-MAT) are: Azoulay Elie (Service de Réanimation Médicale, Hôpital Saint-Louis, Paris); Barbay Virginie (Laboratoire d'Hématologie, CHU Charles Nicolle, Rouen); Benhamou Ygal (Service de Médecine Interne, CHU Charles Nicolle, Rouen); Bordessoule Dominique (Service d'Hématologie, Hôpital Dupuytren, Limoges); Charasse Christophe (Service de Néphrologie, Centre Hospitalier de Saint-Brieuc); Chauveau Dominique (Département de Néphrologie et Transplantation d'Organes, CHU Rangueil, Toulouse); Choukroun Gabriel (Service de Néphrologie, Hôpital Sud, Amiens); Coindre JeanPhilippe (Service de Néphrologie, CH Le Mans); Coppo Paul (Service d'Hématologie, Hôpital Saint-Antoine, Paris); Corre Elise (Service d'Hématologie, Hôpital SaintAntoine, Paris); Delmas Yahsou (Service de Néphrologie, Hôpital Pellegrin, Bordeaux); Deschenes Georges (Service de Néphrologie Pédiatrique, Hôpital Robert Debré, Paris); Devidas Alain (Service d'Hématologie, Hôpital Sud-Francilien, Corbeil-Essonnes); Fain Olivier (Service de Médecine Interne, Hôpital Saint-Antoine, Paris); Frémeaux-Bacchi Véronique (Laboratoire d'Immunologie, Hôpital Européen Georges Pompidou, Paris); Galicier Lionel (Service d'Immunopathologie, Hôpital SaintLouis, Paris); Grange Steven (Service de Réanimation, CHU Charles Nicolle, Rouen); Guidet Bertrand (Service de Réanimation Médicale, Hôpital Saint-Antoine, Paris); Halimi Jean-Michel (Service de Néphrologie Pédiatrique,
Hôpital Bretonneau, Tours); Hamidou Mohamed (Service de Médecine Interne, Hôtel-Dieu, Nantes); Herbrecht Raoul (service d'Oncologie et d'Hématologie, Hôpital de Hautepierre, Strasbourg); Jacobs Frédéric (Service de Réanimation Médicale, Hôpital Antoine Béclère, Clamart); Joly Bérangère (Service d'Hématologie Biologique, Hôpital Lariboisière, Paris); Kanouni Tarik (Unité d'Hémaphrèse, Service d'Hématologie, CHU de Montpellier); Lautrette Alexandre (Service de Néphrologie Pédiatrique B, Hôpital Hôtel-Dieu, ClermontFerrand); Le Guern Véronique (Unité d'Hémaphérèse, Service de Médecine Interne, Hôpital Cochin, Paris); Loirat Chantal (Service de Néphrologie Pédiatrique, Hôpital Robert Debré, Paris); Mira Jean-Paul (Service de Réanimation Médicale, Hôpital Cochin); Moulin Bruno (Service de Néphrologie, Hôpital Civil, Strasbourg); Mousson Christiane (Service de Néphrologie, CHU de Dijon); Ojeda Uribe Mario (Service d'Hématologie, Hôpital Emile Muller, Mulhouse); Ouchenir Abdelkader (Service de Réanimation, Hôpital Louis Pasteur, Le Coudray); Parquet Nathalie (Unité de Clinique Transfusionnelle, Hôpital Cochin, Paris); Peltier Julie (Urgences Néphrologiques et Transplantation Rénale, Hôpital Tenon, Paris); Perez Pierre (Service de Réanimation polyvalente, CHU de Nancy); Poullin Pascale (Service d'hémaphérèse et d'autotransfusion, Hôpital la Conception, Marseille); Pouteil-Noble Claire (Service de Néphrologie, CHU Lyon-Sud, Lyon); Presne Claire (Service de Néphrologie, Hôpital Nord, Amiens); Provôt François (Service de Néphrologie, Hôpital Albert Calmette, Lille); Ribeil Jean-Antoine (Service de Thérapie Cellulaire, Hôpital Necker-Enfants Malades, Paris); Rondeau Eric (Urgences Néphrologiques et Transplantation Rénale, Hôpital Tenon, Paris); Saheb Samir (Unité d'Hémaphérèse, Hôpital la Pitié-Salpétrière, Paris); Schlemmer Benoît (Service de Réanimation Médicale, Hôpital Saint-Louis, Paris); Seguin Amélie (Service de Réanimation Médicale, CHU de Caen); Stépanian Alain (Service d'Hématologie Biologique, Hôpital Lariboisière, Paris); Vernant Jean-Paul (Service d'Hématologie, Hôpital la Pitié-Salpétrière, Paris); Veyradier Agnès (Service d'Hématologie Biologique, Hôpital Lariboisière, Paris); Vigneau Cécile (Service de Néphrologie, Hôpital Pontchaillou, Rennes); Wynckel Alain (Service de Néphrologie, Hôpital Maison Blanche, Reims); Zunic Patricia (Service d'Hématologie, Groupe Hospitalier Sud-Réunion, la Réunion).

\section{Abbreviations}

AKI: Acute Kidney Injury; eGFR: Estimated Glomerular Filtration Rate; GTMA: Gemcitabine-induced Thrombotic Microangiopathy; HUS: Hemolytic Uremic Syndrome; LDH: Lactate Dehydrogenase; RRT: Renal Replacement Therapy; TMA: Thrombotic Microangiopathy; TPE: Therapeutic Plasma Exchange; TTP: Thrombocytopenic Thrombotic Purpura 


\section{Supplementary Information}

The online version contains supplementary material available at https://doi. org/10.1186/s12882-021-02470-3.

\section{Additional file 1.}

\section{Authors' contributions}

MG and SG performed and design the research, and analysed the data. MG SG and PC wrote the paper. All authors provided cases and have read and approved the final version of the manuscript.

\section{Funding}

None.

\section{Availability of data and materials}

The datasets used and/or analysed during the current study are available from the corresponding author on reasonable request.

\section{Declarations}

\section{Ethics approval and consent for participate}

All patients and/or parents/guardians provided written informed consent for entry into the current study. This study was approved by our institutional review board (Rouen University Hospital) in accordance with the Declaration of Helsinki, and the French Data Protection Authority ("Commission Nationale Informatique et Libertés," CNIL, authorization n911,539, and "Comité consultatif sur le traitement de l'information en matière de recherche dans le domaine de la santé," CCTIRS, authorization n'11.537, Paris, France).

\section{Consent for publication}

Not applicable.

\section{Competing interests}

PC, SG and VFB are members of the Clinical Advisory Board for Alexion. PC and $Y G$ are members of the Clinical Advisory Board for Sanofi and Octapharma. PC received financings from Roche Pharma. SG received grants from Alexion.

\section{Author details}

${ }^{1}$ Medical Intensive Care Unit, Rouen University Hospital, 37 boulevard Gambetta, 76031 Rouen Cedex, France. ${ }^{2}$ French TMA Reference Centre, Hopital Saint-Antoine, Sorbonne Université, AP-HP, Paris, France. ${ }^{3}$ Department of Nephrology, Conception University Hospital, APHM, Marseille, France. ${ }^{4}$ Department of Nephrology, Lille University Hospital, Lille, France. ${ }^{5}$ Department of Nephrology, Amiens University Hospital, Amiens, France. ${ }^{6}$ Department of Nephrology, Le Mans General Hospital, Le Mans, France. 'Department of Nephrology, E. Herriot Hospital, Lyon I university, Lyon, France. ${ }^{8}$ Department of Nephrology, Georges Pompidou Hospital, APHP, Paris, France. 'Department of Nephrology, Rouen University Hospital, Rouen, France. ${ }^{10}$ Department of Pathology, Rouen University Hospital, Rouen, France. ${ }^{11}$ Department of Internal Medicine, Rouen University Hospital, Rouen, France. ${ }^{12}$ Department of Biological Hematology, Lariboisière University Hospital, APHP, Paris, France. ${ }^{13}$ Department of immunology, Georges Pompidou Hospital, APHP, Paris, France. ${ }^{14}$ Department of Hematology, Hopital Saint-Antoine, Sorbonne Université, AP-HP, Paris, France.

Received: 7 February 2021 Accepted: 1 July 2021

Published online: 21 July 2021

\section{References}

1. Kremer Hovinga JA, Coppo P, Lämmle B, et al. Thrombotic thrombocytopenic purpura. Nat Rev Dis Primer. 2017;3:17020.

2. Al-Nouri ZL, Reese JA, Terrell DR, Vesely SK, George JN. Drug-induced thrombotic microangiopathy: a systematic review of published reports. Blood. 2015;125(4):616-8.

3. Casper ES, Green MR, Kelsen DP, et al. Phase II trial of gemcitabine (2,2'difluorodeoxycytidine) in patients with adenocarcinoma of the pancreas. Investig New Drugs. 1994;12(1):29-34.
4. Fung MC, Storniolo AM, Nguyen B, et al. A review of hemolytic uremic syndrome in patients treated with gemcitabine therapy. Cancer. 1999;85(9): 2023-32.

5. Flombaum CD, Mouradian JA, Casper ES, Erlandson RA, Benedetti F. Thrombotic microangiopathy as a complication of long-term therapy with gemcitabine. Am J Kidney Dis. 1999;33(3):555-62.

6. Glezerman I, Kris MG, Miller V, Seshan S, Flombaum CD. Gemcitabine nephrotoxicity and hemolytic uremic syndrome: report of 29 cases from a single institution. Clin Nephrol. 2009;71(2):130-9.

7. Izzedine H, Isnard-Bagnis C, Launay-Vacher V, et al. Gemcitabine-induced thrombotic microangiopathy: a systematic review. Nephrol Dial Transplant. 2006;21(11):3038-45.

8. Zupancic M, Shah PC, Shah-Khan F. Gemcitabine-associated thrombotic thrombocytopenic purpura. Lancet Oncol. 2007;8(7):634-41.

9. Dasanu CA. Gemcitabine: vascular toxicity and prothrombotic potential. Expert Opin Drug Saf. 2008;7(6):703-16.

10. Gore EM, Jones BS, Marques MB. Is therapeutic plasma exchange indicated for patients with gemcitabine-induced hemolytic uremic syndrome? I Clin Apher. 2009;24(5):209-14.

11. Francis KK, Kalyanam N, Terrell DR, Vesely SK, George JN. Disseminated malignancy misdiagnosed as thrombotic thrombocytopenic Purpura: a report of 10 patients and a systematic review of published cases. Oncologist. 2007;12(1):11-9.

12. Lechner K, Obermeier HL. Cancer-related microangiopathic hemolytic anemia: clinical and laboratory features in 168 reported cases. Medicine (Baltimore). 2012;91(4):195-205.

13. Oberic L, Buffet M, Schwarzinger M, et al. Cancer awareness in atypical thrombotic microangiopathies. Oncologist. 2009;14(8):769-79.

14. Legendre CM, Licht C, Muus P, et al. Terminal complement inhibitor eculizumab in atypical hemolytic-uremic syndrome. N Engl J Med. 2013;368(23):2169-81.

15. Grall $M$, Provôt $F$, Coindre JP, et al. Efficacy of Eculizumab in gemcitabineinduced thrombotic Microangiopathy: experience of the French thrombotic Microangiopathies reference center. Blood. 2016;128(22):136.

16. Fakhouri F, Zuber J, Frémeaux-Bacchi V, Loirat C. Haemolytic uraemic syndrome. Lancet. 2017;390(10095):681-96.

17. Le Clech A, Simon-Tillaux N, Provôt F, et al. Atypical and secondary hemolytic uremic syndromes have a distinct presentation and no common genetic risk factors. Kidney Int. 2019;95:1443.

18. Al Ustwani O, Lohr J, Dy G, et al. Eculizumab therapy for gemcitabine induced hemolytic uremic syndrome: case series and concise review. J Gastrointest Oncol. 2014;5(1):E30-3.

19. Starck $M$, Wendtner $C-M$. Use of eculizumab in refractory gemcitabineinduced thrombotic microangiopathy. Br J Haematol. 2013.

20. Rogier T, Gerfaud-Valentin M, Pouteil-Noble C, et al. Clinical efficacy of eculizumab as treatment of gemcitabine-induced thrombotic microangiopathy: a case report. Rev Med Interne Fondee Par Soc Natl Francaise Med Interne. 2016;37:701.

21. Turner JL, Reardon J, Bekaii-Saab T, Cataland SR, Arango MJ. GemcitabineAssociated Thrombotic Microangiopathy: Response to Complement Inhibition and Reinitiation of Gemcitabine. Clin Colorectal Cancer. 2016;1:30178.

22. López Rubio ME, Rodado Martínez R, lllescas ML, et al. Gemcitabine-induced hemolytic-uremic syndrome treated with eculizumab or plasmapheresis: two case reports. Clin Nephrol. 2017;87(2):100-6.

23. Martin $\mathrm{K}$, Roberts $\mathrm{V}$, Chong $\mathrm{G}$, et al. Eculizumab therapy in gemcitabineinduced thrombotic microangiopathy in a renal transplant recipient. Oxf Med Case Rep. 2019;2019(6):omz048.

24. Krishnappa V, Gupta M, Shah $\mathrm{H}$, et al. The use of eculizumab in gemcitabine induced thrombotic microangiopathy. BMC Nephrol. 2018;19(1):9.

25. Gosain R, Gill A, Fuqua J, et al. Gemcitabine and carfilzomib induced thrombotic microangiopathy: eculizumab as a life-saving treatment. Clin Case Rep. 2017:5(12):1926-30.

26. Facchini L, Lucchesi M, Stival A, et al. Role of eculizumab in a pediatric refractory gemcitabine-induced thrombotic microangiopathy: a case report. J Med Case Rep. 2017;11(1):209.

27. Daviet $F$, Rouby F, Poullin P, et al. Thrombotic microangiopathy associated with gemcitabine use: presentation and outcome in a national French retrospective cohort. Br J Clin Pharmacol. 2019;85:403-12.

\section{Publisher's Note}

Springer Nature remains neutral with regard to jurisdictional claims in published maps and institutional affiliations. 